\title{
Türkiye'de Dâhilde İşleme Rejimi Kapsamında Gerçekleştirilen İthalatın Yurtiçi Ara Malı Üretimine Etkisi: ARDL Sınır Testi Yaklaşımı
}

\author{
Buket ALTINÖZ \\ Sorumlu Yazar, Nişantaşı Üniversitesi, Meslek Yüksekokulu, \\ Muhasebe ve Vergi Uygulamaları Bölümü, \\ buket.altinoz@nisantasi.edu.tr,ORCID:0000-0002-4276-4821 \\ Mehmet ALTUNTAS \\ Nişantaşı Üniversitesi, Meslek Yüksekokulu, \\ Lojistik Bölümü, \\ mehmet.altuntas@nisantasi.edu.tr,ORCID:0000-0003-2040-3168
}

\begin{abstract}
Öz
Uluslararası piyasalarda ihraç ürünlerine rekabetçi avantaj kazandıracak ticaret politikaları birçok ülke açısından uygulama alanı bulmaktadır. İhracatı desteklemeye yönelik uluslararası ticaret politikaları anlamında Türkiye'de yoğun olarak kullanılan araçların başında ekonomik etkili gümrük rejimleri gelmektedir. Bu rejimlerden biri de dâhilde işleme rejimidir. Rejim, temel olarak ithal edilen girdilerden üretilen ürünlerin ihracatına dayanmaktadır. Bu çalışmada rejim kapsamında gerçekleştirilen girdi ithalatının yurt içi ara malı üretimine olan etkisi ARDL sınır testi yaklaşımı kullanılarak araştırılmıştır. Türkiye'ye ait 2005-2019 dönemi aylık verileri kullanılarak yapılan analiz sonucunda uzun dönemde dâhilde işleme vergisi kapsamında yapılan ithalatın yurtiçi ara malı üretimi üzerinde istatistiksel olarak anlamlı bir etkisi olmadığı tespit edilmiş̧ir. Kısa dönemde ise söz konusu ithalat pozitif fakat oldukça küçük bir etkiye sahiptir.
\end{abstract}

Anahtar kelimeler: Dahilde işleme rejimi, ithalat, ARDL, Türkiye.

Jel sınıflandırma kodları: B17; F19; B23.

The Effect of Import in the context of Inward Processing Regime on Domestic Intermediate Good Production in Turkey: ARDL Boundary Testing Approach ${ }^{1}$

\begin{abstract}
Trade policies that give competitive advantage to export products in international markets apply for many countries. Economically efficient custom regimes occur as an extensively used tool in Turkey for international trade policies to support export. One of these regimes is the inward processing regime. The regime is mainly based on the export of products produced from imported materials. In this study, the effect of imports under the inward processing regime on domestic intermediate production is investigated using the ARDL boundary testing approach for the period from 2005 to 2016. As a result of the analysis, it is determined that import in the context of inward processing regime have not statistically significant impact on domestic intermediate production in the long run. In the short run, the import in question has a positive but rather minor effect.
\end{abstract}

Keywords: Inward processing regime, import, ARDL, Turkey.

Jel Classification Codes: B17; F19; B23.

\footnotetext{
${ }^{1}$ Extended abstract is presented at the end of the article.
}

Geliş Tarihi (Received): 24.04.2020 Kabul Edilme Tarihi (Accepted): 14.12.2020

Atıfta bulunmak için/Cite this paper:

Altınöz, B. ve Altuntaş, M. (2020). Türkiye'de dâhilde işleme rejimi kapsamında gerçekleştirilen ithalatın yurtiçi ara malı üretimine etkisi: ARDL sınır testi yaklaşımı, Çankırı Karatekin Üniversitesi IIBF Dergisi, 10 (2), 639-656. Doi: 10.18074/ckuiibfd.726383 


\section{Giriș}

Küresel ekonomi tarihi incelendiğinde bazı ülkelerin korumacı bazı ülkelerin de dışa açık bir uluslararası ticaret politikası uyguladığına ulaşılmaktadır. Bununla birlikte iktisadi karar birimlerinin ihtiyaçlarındaki süreklilik gösteren değişmeler, bilgi ve iletişim teknolojisi altyapısındaki ilerlemeler, küreselleşme hareketleri ve üretim süreçlerindeki gelişmeler ülkelerin daha ağırlıklı olarak serbest uluslararası ticaret politikaları uygulamalarına neden olmuştur.

Ticaretin serbestleşmesi sürecine destek olan unsurlardan birisi de uluslararası iktisadi organizasyonların yaptığı girişimlerdir. Özellikle 20. yüzyılın ilk yarısının sonlarında yürürlüğe giren Gümrük Tarifeleri ve Ticaret Genel Anlaşması'nın tarifelerin indirilmesi yönündeki maddeleri uluslararası ticarete farklı bir boyut kazandırmıştır. $\mathrm{Bu}$ çerçevede geleneksel uluslararası ticaret teorilerinin destek oluşturduğu modern teorilerin gelişmesi hız kazanmış ve serbest ticaret uygulamaları önem kazanmaya başlamıştır.

Uluslararası ticaretin daha etkin ve verimli bir yapıda işlemesi için küresel ölçekte gümrük tarifeleri düşürülmüş ve iktisadi entegrasyonların gelişmesi ile tarife dışı araçlar da azaltılmıştır. Ancak birçok doğrudan ve dolaylı maliyet, uluslararası ticari ilişkilerin nitelik ve nicelik açısından daha hızlı gelişmesinin önünde engeller oluşturmuştur. Burada da her ülke çeşitli politikalar uygulayarak uluslararası ticaretin özendirilmesi, belirli işlemlerin sınırlandırılması ve yapılış şekillerinin değiştirilmesi şeklinde düzenlemelerde bulunmuştur.

Diğer taraftan küresel üretim, merkez ülkelerden transplant üretim tekniği ile çevre ülkelere doğru kayma göstermektedir. Maliyetlerin gün geçtikçe daha fazla önem arz ettiği günümüz piyasalarında rekabet güçlerini korumak isteyen çok uluslu şirketler optimal maliyetle üretim yapabilecekleri ülkelerde üretim merkezi kurma yoluna yönelmişlerdir. Bu çerçevede her bir parçanın farklı bir ülkede üretilip farklı ülkelerde montaj edildiği yeni üretim sistemleri geliştirilmiştir. Burada yatırımcıyı kendi ülkesine çekmek isteyen ekonomi yönetimleri lojistik maliyetleri dikkate alarak gümrükleme süreçlerinde teşvik politikalarını uygulamaya başlamışlardır.

Türkiye'nin coğrafi konumu, sahip olduğu istihdam yapısı ve lojistik eksenli avantajları dikkate alındığında önemli bir ihracat üssü olarak değerlendirilmektedir. $\mathrm{Bu}$ bağlamda ihracatın sürdürülebilir bir şekilde geliştirilmesi ve dolayısıyla döviz kazandırıcı işlemlerin artırılması noktasında teşvike dayalı birçok uluslararası ticaret politikası uygulanmaktadır. Bu politikaların önemli bir aracı da ekonomik etkili gümrük rejimleridir. Gümrük Kanunu'na göre beş farklı ekonomik etkili gümrük rejimi olsa da sağladığı ekonomik değer açısından en yoğun kullanılan rejim, dahilde işleme rejimidir. Bu 
rejim, ihracata dayalı ürünlere uluslararası piyasalarda rekabet gücü kazandırmak için ihraç malının üretimi için gerekli olan ve yurt içi piyasadan temin edilemeyen girdinin gümrük muafiyeti kapsamında ithalatına izin veren bir rejimdir. Bu uygulama yerli ihracatçılara girdi temin eden üreticilerin ürettiği malların ihracat için gerekli kalite ve özelliklere sahip olmaması veya zamanında teslim edilememesi halinde ihracatçılara gereksinim duydukları malları diğer ülkelerden sağlama imkânı sunmaktadır (Başkol, 2016, s. 3). Böylesi bir kolaylık firmaların ihracat açısından uluslararası piyasalardaki rekabet yeteneğini artırırken, yerli üreticilerin de ihraç mallarına yönelik aramalı üretimini artırmaları için de bir teşvik olarak algılanabilir. Ancak daha ziyade yerli üreticilerin üretimlerine etkisi olmaksızın uygulanan bir dahilde işleme rejimi sisteminin etkin olduğu genel kabul görmektedir.

Literatür incelendiğinde dahilde işleme rejimini konu alan az sayıda çalışma olduğuna ulaşılmaktadır. Bu çalışmalardan bir kısmının uluslararası ticaret verilerinin analiz edilmesine dayandığ oluşturduğu etkilerin analiz edilmesiyle sonuçlandırıldığ 1 görülmektedir. $\mathrm{Bu}$ çalışmada ihracatın ithalata dayalı olarak gerçekleştiği dahilde işleme rejimi kapsamında yapılan ithalatın yurt içi girdi üretimi üzerindeki etkilerinin araştırılmış olması, çalışmanın diğer çalışmalardan farklı olarak literatüre sağlayacağı katkıyı ortaya koymaktadır.

$\mathrm{Bu}$ çerçevede çalışma giriş ve sonuç bölümleri dişında üç bölümden oluşturulmuştur. İkinci bölümde teorik perspektiften dahilde işleme rejimi ve işleyişi ele alınmıştır. Üçüncü bölümde literatür incelenmiş olup, dördüncü ve son bölümde de veri seti, ekonometrik yöntem ve ampirik bulgulara yer verilmiştir.

\section{Dahilde İşleme Rejimi ve İşleyişi}

Uluslararası piyasalarda zaman zaman korumacı politikalar izlense de özellikle İkinci Dünya Savaşı sonrası serbest ticareti teşvik edici çalışmalara önem verilmiştir. Bu bağlamda 1950'li ve 1960'lı yıllarda gümrük tarifelerinin düşürülmesi yönündeki çalışmalar 1980'lerle birlikte tarife dışı araçların da azaltılması noktasında yoğunlaştırılmıştır. Bunu takiben 1990'lı y1llarda uluslararası ticari işlemler için büyük önem arz eden ticari maliyetlere odaklanılmıştır (Pomfret ve Sourdin, 2009, s. 2).

Serbest ticareti benimseyen ülkeler, uluslararası ticaretin gelişmesi ve kolaylaşması noktasında özellikle ihracat eksenli çok sayıda teşvik politikasını hayata geçirmiştir. $\mathrm{Bu}$ çerçevede ihracat kredileri, ihracata yönelik devlet yardımları, vergi istisna ve muafiyetleri, gümrük rejimleri, sigorta ve garanti programları ihracatçı firmalara uygulanan temel desteklerdir. Türkiye özelinde de ekonomik etkili gümrük rejimleri önemli bir teşvik aracı olarak kullanılmaktadır. 
Ekonomik etkili gümrük rejimleri; döviz kazandırıcı işlemleri geliştirmeye, istihdamı sürdürülebilir bir şekilde artırmaya ve sonuç olarak ekonomik büyümeyi hızlandırmaya dayalı gümrük rejimlerini kapsamaktadır. Gümrük Kanunu'na göre antrepo, dahilde işleme, gümrük kontrolü altında işleme, geçici ithalat ve hariçte işleme olmak üzere beş farklı ekonomik etkili gümrük rejimi bulunmaktadır. Sağladığı katma değer ve ekonomik büyüklükler üzerinde oluşturduğu etkiler değerlendirildiğinde en yoğun kullanılan rejimin dahilde işleme rejimi olduğu görülmektedir.

Dahilde işleme rejimi, ihracata dayalı ürünlere küresel pazarlarda rekabetçi avantaj kazandırmak amacıyla ihraç ürünlerinin üretimi için gerekli olan ve yurt içi piyasalardan temin edilemeyen hammadde, ara malı madde ve işleme tabi tutulacak ambalaj malzemesinin ithalatına ticaret politikası önlemlerine tabi olmaksızın gümrük muafiyetli olarak imkân veren ekonomik etkili bir gümrük rejimidir.

Dolayısıyla rejim, ihracatını gerçekleştirmek kaydıyla malların üretiminde kullanılacak girdilerin ithalatı sürecinde karşılaşılan tarife ve benzeri mali yükümlülüklere muafiyet tanıyan bir ihracat teşvik sistemidir. İthalat sürecinde sağlanan muafiyetler, dünya fiyatlarından girdi temin eden ihracatçı firmalara uluslararası rekabetçi güç kazandırmaktadır. Ayrıca bu rejim ile ihracat pazarlarının geliştirilmesi, ihracata dayalı ürünlerin çeşitlendirilmesi ve sürdürülebilir ihracat artışlarının sağlanması da amaçlanmıştır.

Dahilde İşleme Rejimi Tebliği'ne göre bu rejim, dahilde işleme izni ve dahilde işleme izin belgesi olmak üzere iki yöntemle kullanılabilmektedir. Daha küçük çaplı uluslararası ticari işlemlerde dahilde işleme izni süreci takip edilirken, büyük çaplı işlemlerde dahilde işleme izin belgesi süreci uygulanmaktadır. Dahilde işleme izni prosedürleri gümrük idarelerince yönetilirken; dahilde işleme izin belgesi prosedürleri bakanlığa bağlı İhracat Genel Müdürlüğünce takip edilmektedir.

Gümrük Kanunu'nun Dahilde İşleme Rejimi başlıklı 108. maddesinde ve Dahilde İşleme Rejimi Tebliği’nin Dahilde İşleme Tedbirleri başlıklı 4. maddesinde Şartlı Muafiyet Sistemi ve Geri Ödeme Sistemi olmak üzere rejimin iki farklı türü olduğu belirtilmiştir. Şartlı muafiyet sistemi; ihracı taahhüt edilen işlem görmüş ürünün üretiminde kullanılan ve serbest dolaşıma girmemiş ithal ham madde, yarı mamul ve mamulün ticaret politikası önlemlerine tabi tutulmaksızın, vergisi teminata bağlı olmak koşuluyla bedelli ve/veya bedelsiz olarak ithal edilmesi ve ihracat taahhüdünün gerçekleşmesini takiben alınan teminatın iade edilmesidir. Burada önemli olan girdinin serbest dolaşımda olmamasıdır.

Geri Ödeme Sistemi ise, dahilde işleme izin belgesi veya dahilde işleme izni kapsamında daha önceden serbest dolaşıma giren hammadde, yarı mamul madde, mamul ile değişmemiş eşya, ambalaj ve işletme malzemesinden elde edilen işlem 
görmüş ürünün ihraç edilmesi durumunda ithalat esnasında tahsil edilen vergilerin (işletme malzemesine ilişkin katma değer vergisi ve özel tüketim vergisi hariç) geri ödenmesidir (Dal, 2015, s. 7).

Her iki sistem de gümrük tarifesi ve benzeri mali yükümlülükler eksenli teşvik mekanizmasına dayanırken uygulama süreçlerinde farklılıklar bulunmaktadır. Şartlı muafiyet sisteminde serbest dolaşımda olmayan girdinin ticaret politikası önlemleri uygulanmadan belirli orandaki bir teminatla vergi ödemesi yapılmadan ihracat taahhüt ve zorunluluğu ile ithalatı söz konusu iken; geri ödeme sisteminde herhangi bir teminat ve ihracat taahhüdü olmaksızın ticaret politikası önlemleri ile vergisi ödenerek serbest dolaşıma alınan girdi ithalatı söz konusudur (Tekin, 2017, s. 199).

Sağladığı muafiyetler ile yerleşik firmalara uluslararası piyasalarda rekabet gücü kazandırması, üretim sürecinde serbest dolaşımdaki eşdeğer eşyanın kullanımına olanak vermesi ve ödenmiş vergilerin geri alınmasına olanak sağlaması rejimin avantajlı yönlerini ortaya koymaktadır. Bununla birlikte rejime kamu gelirlerinin bir kısmından vazgeçiliyor olması, yerli hammadde ve ara malı üreticilerini zor durumda bırakması gibi eleştiriler de getirilmektedir (Sayılgan ve Şenol, 2010, s. 40).

Esasında dahilde işleme rejimine yönelik temel beklenti yurtiçi üretime herhangi bir etkide bulunmaksızın bu rejimin ihracata katkı sağlamasının garanti edilmesidir. Dolayısıyla bu beklenti ile dahilde işleme rejiminden faydalanılarak aramalı ithal edildiğinde, aynı ürünü yurtiçinde üreten üreticilerin zarar görmemesi gerekir. Aksi takdirde yurtiçi aramalı üreticileri haksız rekabet koşulları altında faaliyet göstermek durumunda kalarak rekabet güçlerini kaybedebilirler (Şenol, 2008, s. 24). Bu kapsamda dahilde işleme rejiminin etkin işleyişi yurtiçi üreticilerin üretimlerine ve çıkarlarına zarar vermediği sürece geçerli olmaktadır ve bu çerçevede yurtiçi piyasadaki üretim dengesinin ve rekabetin bozulmaması amacı doğrultusunda dahilde işleme izin belgelerinin düzenlenmesi esas alınmaktadır (Takım ve Ersungur, 2010, s.295).

\section{Literatür Araştırması}

Ulusal ve uluslararası literatür incelendiğinde dahilde işleme rejiminin ekonomik etkilerini araştıran sınırlı sayıda çalışma olduğuna ulaşılmaktadır. Bu çalışmaların bir kısmı sadece durum tespitine yönelik temel verilerin yorumlanmasına bir kısmı da rejim ile ihracat arasındaki ilişkilerin analiz edilmesine dayanmaktadır. Bununla birlikte teorik olarak bazı çalışmalarda rejimin yurt içi piyasalarda gerçekleştirilen üretimi olumsuz etkilediği de belirtilmiştir. Bu bağlamda ulusal ve uluslararası literatürde dahilde işleme rejimini konu alan ampirik çalışmalara aşağıda yer verilmiştir. 
Öncelikle mevcut literatürde dahilde işleme rejimi uygulamasının dış ticaret dengesi ve cari açıkla ilişkisinin yaygın olarak incelendiği dikkat çekmektedir. Bu kapsamda Eryüzlü (2013) 1996-2013 dönemi için dâhilde işleme rejimi ve diş ticaret ilişkisini analiz etmiştir. Yapılan analize bağlı olarak rejim kapsamında gerçekleştirilen ihracat ile cari açık arasında güçlü bir nedensellik ilişkisi olduğu sonucuna ulaşılmıştır. Mete ve Yıldız (2017) tarafindan Engle-Granger eşbütünleşme testi ve hata düzeltme modeli kullanılarak gerçekleştirilmiştir. 2003:1-2016:2 dönemi için dahilde işleme rejimi kapsamındaki sektörel ihracat ve ithalatın cari dengeye etkisini araştırmışlardır. Rejim kapsamındaki sanayi ihracat1, sanayi ithalatı ve maden ihracatının cari denge üzerinde olumlu etkilerinin olduğu sonucuna ulaşılmıştır. Şahin ve Tekin (2019) 1996-2017 dönemini için Türkiye'de dahilde işleme rejimi kapsamında gerçekleştirilen ihracat ve ithalatın dış ticaret dengesi üzerine olan etkisini araştırmışlardır. Johansen eşbütünleşme testi, hata düzeltme modeli ve Granger nedensellik testinin uygulandığı çalışmada rejim kapsamındaki ihracat ve ithalatın dış ticaret dengesi üzerinde etkili olduğu sonucuna ulaşılmıştır.

Dış ticaretin yanı sıra rekabet ve istihdama da odaklanan Gençosmanoğlu (2016) 2002-2014 dönemi için değişik ticaret endeksleri vasıtasıyla dahilde işleme rejiminin Türkiye'de dış ticaretin, istihdamın ve rekabet gücünün geliştirilmesine katkılarını incelemiştir. Çalışmada rejimin ticaret akımlarında, istihdamda ve rekabet gücünde ortalamanın üzerinde artışlara neden olmadığı ve sistemin gümrük tarifelerinden ve politika önlemlerinden muaf olmak için ihracatç1 firmalarca kullanıldığı yönünde somut bulgulara rastlanmadığ sonuçlarına ulaşılmıştır. Görg (2000) seçilmiş 14 sanayi sektörü için 1988-1994 dönemine ait verilerle ABD'den dahilde işleme rejimi kapsamında yapılan ithalatın Avrupa Birliği ülkelerindeki ihracatın ithalatı karşılama oranı üzerindeki etkisini panel veri analizi yöntemiyle analiz etmiştir. Sonuç olarak ABD'de rejim kapsamında yapılan ithalatın, ihracatın ithalatı karşılama oranı üzerinde pozitif etkisinin olduğu bulgusu elde edilmiştir (aktaran Mete ve Yıldız, 2017, s. 42). Dal (2015) ise dahilde işleme rejimi kapsamındaki ihracat ile döviz kuru ilişkini ele almıştır. 2002-2014 dönemi için dahilde işleme rejimi verilerini kullanarak işlenmiş ve işlenmemiş ürün ihracatı kapsamında Türkiye'de ihracat ve döviz kuru arasındaki ilişkiyi analiz etmiştir. Kısa ve uzun dönemli bu ilişki analizinde Johansen eş bütünleşme testi ve vektör hata düzeltme modeli kullanılmıştır. Kurulan model ile işlenmemiş ürün ihracatının uzun dönemde işlenmiş ürün ihracatına göre döviz kuru, dış alem geliri ve sermaye stokundaki değişime daha fazla duyarlı olduğu; kısa dönemde ise işlenmiş ürün ihracatının her üç değişkene de duyarlı olduğu; ancak işlenmemiş ürün ihracatının sermaye stokundaki değişimden etkilenmediği sonuçlarına ulaşılmıştır.

Diş ticaret ve cari açığa ek olarak temel bir makroekonomik gösterge olarak kabul edilen ekonomik büyüme ile dahilde işleme rejimi arasındaki ilişki de yapılan bazı çalışmalarda ele alınmıştır. Yıldız ve Mete (2018) 2002(1)-2016(2) dönemi için 
Türkiye'de dahilde işleme rejimi kapsamında gerçekleştirilen sektörel ithalat ile reel Gayri Safi Yurtiçi Hasıla (GSYH) arasındaki ilişkileri zaman serisi analizleri ile test etmişlerdir. Çalışmada tarımsal dahilde işleme rejimi kapsamında gerçekleştirilen ithalat ile ekonomik büyüme arasında bir nedensellik ilişkisi olmadığı, maden ve sanayi sektöründeki dahilde işleme rejimine bağlı olarak gerçekleştirilen ithalatın reel GSYH'deki değişimin nedeni olduğu ve dolayısıyla rejimin ithalata dayalı büyümeye sebebiyet verdiği sonucuna ulaşılmıştır. Bustillo ve Rodriguez (2011) 1995-2000 dönemi için panel veri analizi yöntemiyle Avrupa Birliği ülkelerinde ticari birleşme hareketlerinin ticaret rejimleri üzerindeki etkilerini analiz etmişlerdir. Çalışmada dahilde işleme rejimi kapsamında gerçekleşen ticaret ile ekonomik büyüme arasında pozitif yönlü ve anlamlı bir ilişki olduğu sonucuna ulaşılmıştır.

Tarımsal ürünlere üretimine yönelik olarak Duru, Konuşkan ve Parlakay (2017) tarafından bitkisel yă üretimi ve diş ticareti yapan 26 firmaya rejimin uygulanabilirliğinin ve etkilerinin analizi için anket uygulaması yapılmıştır. Rejimi kullanan 25 firmanın yanıtlarına göre yapılan analizlerde dâhilde işleme rejiminin uygulanmaya başlamasıyla firmaların girdiyi daha kolay ve ucuza temin ettiği, kapasite kullanım oranının arttığı, piyasa payı ve ihracat değerlerinin arttığına ulaşılmıştır. Yine tarım ürünlerini esas alarak, Parlakay ve Duru (2017) dahilde işleme rejiminin uygulanmaya başladığı 1996 yılından itibaren Türkiye'nin işlenmiş tarım ürünleri dış ticaretinin gelişimini Trend Analizi yöntemiyle incelemişlerdir. İşlenmiş tarım ürünleri alanında rejimin kullanılmasının ülke ihracatı ve milli gelire katkı anlamında önemli olduğu, rejimin âtıl kapasitenin değerlendirilmesi ve daha fazla kazanç sağlanması açısından firsat oluşturduğu sonuçlarına ulaşılmıştır.

Ampirik literatür yapılan çalışmalarda dahilde işleme rejiminin ağırlıklı olarak dış ticaret göstergeleri ile ilişkisine odaklanıldığını göstermektedir. Bununla birlikte bu çalışma mevcut literatürde dikkat çeken bir eksikliğe odaklanarak dahilde işleme rejimi uygulamasının yurtiçi aramalı üretim üzerindeki etkisini analiz etmeyi amaç edinmiştir. Dolayısıyla aslında dahilde işleme rejiminin etkin işleyip işlemediğinin, yani bu uygulamamın öngörülen sorunlarından biri olarak yurtiçi aramalı üretimine zarar verip vermediğinin ortaya çıkarılması ile literatürdeki boşluk doldurulmaya çalışılmıştır.

\section{Veri Seti, Metodoloji ve Ampirik Bulgular}

\subsection{Veri Seti ve Model}

Çalışmada dâhilde işleme rejimi kapsamında yapılan ithalatın ara malı üretimi üzerindeki etkisi Türkiye'ye ait 2005-2019 dönemi için aylık veriler kullanılarak test edilmiştir. $\mathrm{Bu}$ amaç etrafında analize dâhil edilen temel açıklayıcı değişken niteliğindeki dâhilde işleme rejimi altında yapılan ithalat tutarları ve bağımlı değişken olarak benimsenen aramalı üretim endeksi Türkiye İstatistik Kurumu 
kaynaklarından temin edilmiştir. Ayrıca faiz oranı, döviz kuru ve üretici fiyat endeksi göstergeleri ara malı üretimine olası etkileri göz önüne alınarak birer kontrol değişkeni olarak modele dâhil edilmiştir. TCMB Elektronik Veri Dağıtım Siteminden temin edilen kontrol değişkenleri sırasıyla, bir yıl ve daha uzun vadeli TL cinsinden açılan mevduatlara uygulanan faiz oranları, nominal dolar kuru ve yurtiçi üretici fiyat endeksini ifade eder. Söz konusu değişkenler ve çalışmanın amacı doğrultusunda oluşturulabilecek temel bir zaman serisi modeli şu şekilde ifade edilebilir:

$\log _{-} u r t_{t}=$

$\alpha_{i}+\beta_{1} \log _{-} i t h_{t}+\beta_{2} \log _{-}$faiz $_{t}+\beta_{3} \log _{-} k u r_{t}+$

$$
\beta_{4} \log \_u f e_{t}+\mu_{t}
$$

Tüm değişkenler modele logaritmik olarak dâhil edilmiştir ve mevsimsel etkilerden arındırılmıştır. Modelde yer alan değişkenler sırasıyla yurtiçi ara malı üretimi (log_urt), ara malı ithalat tutarı (log_ith), faiz oranı (log_faiz), nominal dolar kuru (log_kur) ve üretici fiyat endeksidir (log_ufe).

Tablo 1. Tanımlayıcı İstatistikler

\begin{tabular}{lllllll}
\hline & Mean & Median & Max. & Min. & S.D. & Obs. \\
\hline $\log \_$urt & 1.916 & 1.930 & 2.078 & 1.741 & 0.099 & 178 \\
\hline $\log$ ith & 9.323 & 9.237 & 9.492 & 0.090 & 0.070 & 178 \\
\hline $\log$ faiz & 1.086 & 1.049 & 1.359 & 0.879 & 0.129 & 178 \\
\hline log_kur & 0.319 & 0.253 & 0.804 & 0.067 & 0.201 & 178 \\
\hline $\log$ _ufe & 2.314 & 2.308 & 2.658 & 2.060 & 0.157 & 178 \\
\hline
\end{tabular}

\subsection{Metodoloji}

Ampirik analiz içeren çalışmalarda kullanılan değişkenlere ilişkin birim kök sınaması sonuçların güvenilirliği bakımından önem verilen bir konudur. Buna göre, bu çalışmada öncelikle serilerin durağanlığı yani birim kök içerip içermemesi Augmented Dickey Fuller (ADF) birim kök testi ile incelenmiştir. Bu test Dickey ve Fuller (1979) tarafindan geliştirilmiş olup, teste ilişkin esas denklem şu şekildedir sembolize edilmektedir:

$\Delta Y_{t}=\alpha+\delta Y_{t-1}+\sum_{i=1}^{Z} \theta_{i} \Delta Y_{t-i}+\mu_{t}$

Denklemde yer alan $\Delta, Y_{\mathrm{t}}, t, \mu_{t}$ ve $z$ simgeleri sirasıyla birinci fark operatörünü, her bir seriyi, ele alınan dönemi, hata terimini, bağımlı değişkenin gecikme uzunluğunu ifade eder. Gecikme uzunluğu yaygın olarak Akaike Bilgi Kriterine göre belirlenmektedir. ADF birim kök testinde boş hipotez serilerin birim kök içerdiğini ifade ederken, alternatif hipotez ise serilerin birim kök içermediğini 
ifade etmektedir. Hipotezler $\delta$ parametresine ilişkin elde edilen katsayı ve t istatistik değeri ile sınanır. Ardından Phillips-Perron birim kök testi yardımıyla $\mathrm{ADF}$ testinden elde edilen sonuçların güvenilirliği artırılmıştır.

Değişkenlerin durağanlık testinin tamamlanması ile birlikte, değişkenler arasında bir eşbütünleşme ilişkisinin mevcudiyeti araştırılır ve ardından hem uzun ve kısa dönem katsayı tahmini yapılır. Ele alınan ilişkiyi analiz etmek için çalışmada Pesaran, Shin ve Smith (2001) tarafından geliştirilen Autoregressive DistributedLag (ARDL) sınır testi yaklaşımı uygulanmıştır. Yöntem kısa ve uzun dönem ilişkileri analiz etmeyi sağlamaktadır. Ayrıca yöntemi diğer eş bütünleşme testlerinden ayıran önemli bir özelliği serilerin farklı derecelerde durağan olmaları durumunda ve serilere önceden birim kök testi yapılmaması durumunda da uygulanabilir olmasıdır. Bu avantajlar doğrultusunda ARDL modeli şu şekilde oluşturulmaktadır:

$$
\begin{aligned}
& \Delta \log \_u r t_{t}=\alpha+\sum_{i=1}^{z} \beta_{1 i} \Delta\left(\log \_u r t\right)_{t-i}+\sum_{i=0}^{z} \beta_{2 i} \Delta\left(\log \_i t h_{t-i}+\right.
\end{aligned}
$$

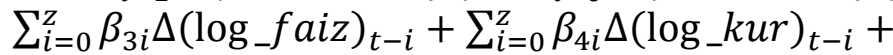

$$
\begin{aligned}
& \sum_{i=0}^{z} \beta_{5 i} \Delta\left(\log \__{-} u f e\right)_{t-i}+\beta_{6} \log \_u r t_{t-1}+\beta_{7} \log \_i t h_{t-1}+ \\
& \beta_{8} \log _{-} \text {faiz }_{t-1}+\beta_{9} \log _{-} \text {kur }_{t-1}+\beta_{10} \log u f e_{t-1}+\varepsilon_{t}
\end{aligned}
$$

Denklemde $\Delta$ bağımlı ve açıklayıcı değişkenlerin gecikmeleri arasındaki farkı ifade eder. Bağımlı ve açıklayıcı değişkenlerdeki her bir gecikme arasındaki fark kısa dönem katsayıları gösterir. Uzun dönem katsayıları ise her bir gecikme değeri katsayısının, bağımlı değişkenin katsayısına oranlanması ile elde edilir. ARDL modeline ait hipotezler şu şekilde kurulur:

$\mathrm{H}_{0}=\beta_{6}=\beta_{7}=\beta_{8}=\beta_{9}=\beta_{10}=0$

$\mathrm{H}_{1}=\beta_{\mathrm{i}}{ }^{\prime}$ lerden en az biri sifirdan farklıdır

İlk hipotez eş bütünleşmenin olmadığını ifade ederken, alternatif hipotez eşbütünleşmenin varlığını gösterir. İfade edilen hipotezlerin test edilmesi için Pesaran vd. (2001) kritik değerler hesaplamışlardır. Bu kritik değerler iki kısımdan oluşmaktadır. Birincisinde tüm değişkenlerin birinci farkta entegre olduğu (I(1)), ikincisinde ise entegrasyon derecesinin sıfır olduğu $(\mathrm{I}(0))$ varsayılır. I(0) ve I(1) durumları için hesaplanan kritik değerler arasında oluşan banta göre bir sonuca varılır. Buna göre hesaplanan $F$ istatistik değeri üst sınır-I(1) değerinden yüksekse $\mathrm{H}_{0}$ hipotezi reddedilerek eş bütünleşmenin olduğu sonucuna ulaşılır. Hesaplanan $\mathrm{F}$ istatistik değeri alt sınırın- $\mathrm{I}(0)$ altındaysa $\mathrm{H}_{0}$ kabul edilir. $\mathrm{H}_{0}$ 'ın reddedildiği durumda bir sonraki aşamaya geçilerek Hata Düzeltme Modeli uygulanır. Bu aşamada hata düzeltme terimi kısa dönem dinamikleri elde etmek üzere şu şekilde tanımlanmaktadır: 


$$
\begin{aligned}
& \Delta{\log \_u r t_{t}}=\alpha+\sum_{i=1}^{z} \beta_{1 i} \Delta\left(\log \_u r t_{t-i}+\sum_{i=0}^{z} \beta_{2 i} \Delta\left(\log \_i t h_{t-i}+\right.\right. \\
& \sum_{i=0}^{z} \beta_{3 i} \Delta\left(\log _{-} \text {faiz }\right)_{t-i}+\sum_{i=0}^{z} \beta_{4 i} \Delta\left(\log _{-} k u r\right)_{t-i}+ \\
& \sum_{i=0}^{0} \beta_{5 i} \Delta\left(\log \__{-} u f e\right)_{t-i}+\beta_{6 i} E C T_{t-1}+\vartheta_{t}
\end{aligned}
$$

Kısa dönem için elde edilen katsayı tahmin sonuçlarının yanı sıra hata düzeltme katsayısına (ECT) ilişkin elde edilen sonuç modelin geçerliliği için değerlendirme kapsamına alınır. Buna göre $E C T_{t-1}$ katsayısının negatif ve anlamlı olması kısa dönemde var olan dengesizliklerin uzun dönemde ortadan kalkacağı anlamına gelir.

\subsection{Ampirik Sonuçlar}

Tablo 2 çalışmada kullanılan değişkenlere ilişkin birim kök test sonuçlarını içermektedir. Hem ADF hem de PP birim kök testi sonuçlarına göre tüm

\begin{tabular}{|c|c|c|}
\hline & ADF & PP \\
\hline Değişken & t-Statistic(Prob.) & t-Statistic(Prob.) \\
\hline log_urt & $-2.142(0.517)$ & $-2.379(0.389)$ \\
\hline log_ith & $-7.686(0.078)$ & $-4.016(0.001)$ \\
\hline log_faiz & $-1.709(0.424)$ & $-1.174(0.685)$ \\
\hline log_kur & $-1.863(0.669)$ & $-1.718(0.739)$ \\
\hline log_ufe & $-0.894(0.953)$ & $-0.836(0.959)$ \\
\hline$\Delta \log \_$urt & $-4.213(0.005)$ & $-14.675(0.000)$ \\
\hline$\Delta \log \_$ith & $-17.916(0.000)$ & $-21.187(0.000)$ \\
\hline$\Delta \log _{\text {_faiz }}$ & $-3.099(0.028)$ & $-10.217(0.000)$ \\
\hline$\Delta \log _{\text {Lnkur }}$ & $-6.775(0.000)$ & $-8.993(0.000)$ \\
\hline$\Delta \overline{\log \_ \text {ufe }}$ & $-8.313(0.000)$ & $-7.750(0.000)$ \\
\hline
\end{tabular}
değişkenlerin birinci farkta durağan olduğu söylenebilir.

Tablo 2: Birim Kök Testi Sonuçları

Durağanlık, yani birim kök, sınaması ile değişkenlerin I(2) olmadığı belirlendikten sonra ARDL modelinin uygulanması aşamasına geçilmiştir. Öncelikle en uygun ARDL modeli olarak ARDL $(2,1,2,4,0)$ belirlendikten sonra modele ilişkin sonuçlar Tablo 3'te özetlenmiştir. Tablo 3'te eşbütünleşme testi, uzun dönem katsayılar ve kısa dönem hata düzeltme modeli katsayıları ile tanısal test sonuçları yer almaktadır. 
Tablo 3: ARDL Uzun ve Kısa Dönem Sonuçlar (bağımlı değişken: log_urt)

\begin{tabular}{lcr}
\hline Eşbütünleşme & F-istatistik & {$[\mathbf{I}(\mathbf{0})-\mathbf{I}(\mathbf{1})]$} \\
\hline ARDL(2,1,2,4,0) & 5.651 & $3.29-4.37^{*}$ \\
\hline Kısa dönem ECM sonuçları & Katsayı & \\
\hline C & 0.160 & \\
log_urt(-1) & $-0.096^{*}$ & \\
log_ith(-1) & 0.012 & \\
log_faiz(-1) & $-0.047^{*}$ & \\
log_kur(-1) & $0.063^{* *}$ & \\
log_ufe(-1) & -0.025 & \\
d(log_urt(-1)) & $-0.250^{*}$ & \\
d(log_ith) & $0.044^{* *}$ & \\
d(log_faiz) & 0.038 & \\
d(log_kur) & 0.023 & \\
ECT(-1) & $-0.096^{*}$ & \\
\hline Uzun dönem sonuçlar & Katsayı & \\
\hline C & 1.665 & 0.516 \\
\hline log_ith & 0.133 & \\
\hline log_faiz & $-0.495^{*}$ & \\
\hline log_kur & $0.661^{*}$ & \\
\hline log_ufe & -0.265 & \\
\hline Tanısal test sonuçları & İstatistik & \\
\hline Breusch-Godfrey Serial & 1.257 & \\
Correlation LM Test & & \\
\hline Heteroskedasticity Test: & 0.791 & \\
Breusch-Pagan-Godfrey & 14.714 & \\
\hline Jarque-Bera Normallik & & \\
Testi & 0.612 & \\
\hline Ramsey-Reset Testi & & \\
\hline *ve** sırasiyla \%1 ve\%5 istatistiksel anlamllık düzeylerini ifade eder. & \\
Not: ARDL modelinin belirlenmesinde Akaike Bilgi Kriterinden faydalanılmıstrr. & \\
\hline & & \\
\hline
\end{tabular}

İlk olarak uzun dönem katsayı tahmin sonuçlarına göre dâhilde işleme rejimi kapsamında yapılan ithalatın yurtiçi ara malı üretimi üzerinde istatistiksel olarak anlamlı bir etkisi yoktur. Bu sonuç esasında dahilde işleme rejimi ile Türkiye'de yerli aramalı üretimi yerine ihraç edilecek malların üretiminde kullanılan girdilerin ithal edilmesinin daha avantajlı olduğunu göstermektedir. Bu ise ihracat odaklı bir dış ticaretin dünya genelinde olduğu gibi Türkiye'de de benimsenmiş olmasının kabul edilebilir bir sonucu olarak görülebilir. Öte yandan söz konusu rejimin aşırı ithal girdi bağımlılığına ve böylece cari işlemler dengesine zarar vermesinin önüne geçilmesi hususu oldukça önem kazanmaktadır. Kısa dönem 
hata düzeltme modeli sonuçları da uzun dönem sonuçlarla aynı doğrultuda olarak değerlendirilebilir. Böylece kısa dönemde dâhilde işleme vergisi kapsamındaki ithalat tutarında ortaya çıkan bir birimlik artışın yurtiçi ara malı üretimini yaklaşık yüzde 0.04 artırdığı söylenmekle birlikte, bu pozitif etkisinin önemsiz boyutlarda olması kısa ve uzun dönem sonuçların tutarlılığını artırmaktadır. Bununla birlikte kısa dönem için tespit edilen yurtiçi üretim artışı etkisinin uzun dönemde de sürdürülebilirliğinin sağlanmasına karar verilmesi yine cari açık, TL'nin değeri ve/veya ithal girdi bağımlılığının boyutu ile ilgilidir. Dolayısıyla bu noktada analiz bulgularından elde edilen sonuç ihracat odaklı ticaret ile uyumlu olarak değerlendirilse de ülkenin dış ticaret göstergeleri bakımından mevcut durumu ile farklı değerlendirmelere de açıktır.

Tablo 3'te yer alan tanısal testler ile modelin ekonometrik açıdan uygunluğu test edilmiştir. Buna göre yapılan Breusch-Godfrey serial korelasyon LM testi ile otokorelasyon, Heteroskedasticity testi sonucunda değişen varyans problemi olmadığı kanısına varılmıştır. Ayrıca modelin istikrarlı olup olmadığı CUSUM ve CUSUMQ testleri ile sınanmıştır. Sonuçlar Şekil 1'de yer almaktadır ve analize konu olan dönemde herhangi bir kırılmanın olmadığı ve modelin istikrarlı olduğu gözlenmektedir.
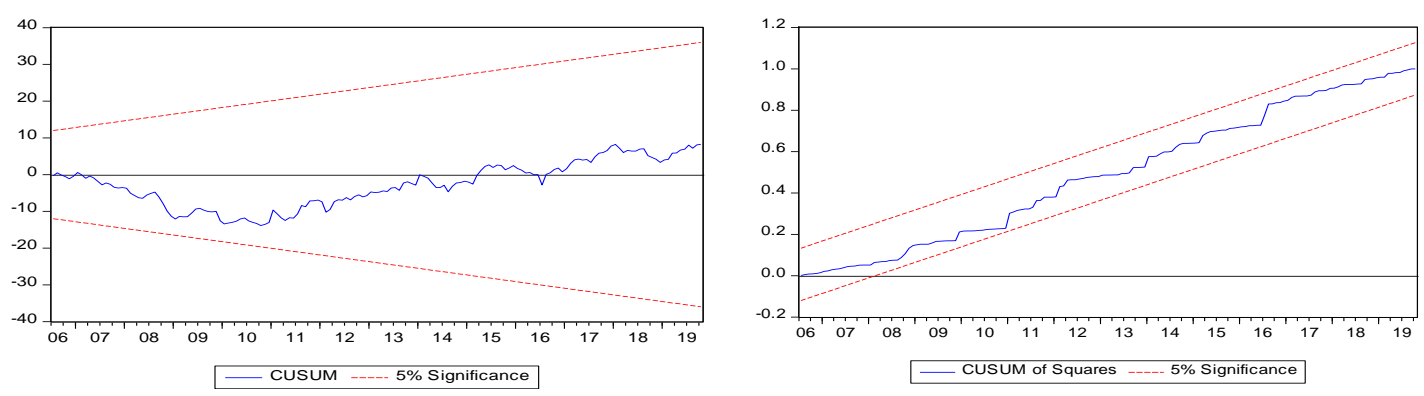

\section{Şekil 1: CUSUM ve CUSUMQ Test Sonuçları}

Uzun ve kısa dönem ARDL analizinin ardından değişkenler arasındaki nedensel ilişkilerin araştırılması için Hata düzeltme modeline dayalı Granger nedensellik testi uygulanmıştır. Sonuçlar yurtiçi ara malı üretiminden dahilde işleme tabi ithalata doğru tek yönlü bir nedensellik ilişkisini göstermektedir. ARDL sonuçları ile uyumlu olarak dahilde işlem rejimi kapsamındaki ithalat ile yurtiçi girdi üretimi arasında herhangi bir nedensel ilişkiye rastlanmamıştır. Ayrıca faiz ile yurtiçi girdi üretimi ve döviz kuru ile dahilde işleme rejimi kapsamındaki ithalat arasında çift yönlü ilişki tespit edilmiştir. Buna ek olarak döviz kurundan yurtiçi girdi üretimine, üretici fiyat endeksinden dahilde işleme rejimi kapsamındaki ithalata, DİR rejimi kapsamındaki ithalattan faiz oranına ve üretici fiyat endeksinden faiz oranlarına doğru tek yönlü nedensellik ilişkisi tespit edilmiştir. 
Tablo 4: VEC Granger Causality/blocexogeneity Wald Test Sonuçları

\begin{tabular}{lll}
\hline Bağımlı Değişken: d(log_urt) & Chi-sq & Prob. \\
\hline d(log_ith) & 1.789 & 0.408 \\
d(log_faiz) & $8.723^{* *}$ & 0.012 \\
d(log_kur & $6.574^{* *}$ & 0.037 \\
d(log_ufe) & 1.490 & 0.474 \\
\hline Bağımlı Değişken: d(log_ith) & Chi-sq & Prob. \\
\hline d(log_urt) & $9.527^{*}$ & 0.008 \\
d(log_faiz) & 0.256 & 0.879 \\
d(log_kur) & $20.731^{*}$ & 0.000 \\
d(log_ufe) & $37.322^{*}$ & 0.000 \\
\hline Bağımlı Değişken: d(log_faiz) & Chi-sq & Prob. \\
\hline d(log_urt) & $6.028^{* * *}$ & 0.049 \\
d(log_ith) & $15.026^{*}$ & 0.000 \\
d(log_kur) & 3.654 & 0.160 \\
d(log_ufe) & $10.056^{*}$ & 0.006 \\
\hline Bağımlı Değişken: d(log_kur) & Chi-sq & Prob. \\
\hline d(log_urt) & 0.107 & 0.947 \\
d(log_ith) & $6.840^{* *}$ & 0.032 \\
d(log_faiz) & 1.678 & 0.432 \\
d(log_ufe) & 0.513 & 0.773 \\
\hline Dependent Variable: d(log_ufe) & Chi-sq & Prob. \\
\hline d(log_urt) & 2.387 & 0.303 \\
d(log_ith) & 2.267 & 0.321 \\
d(log_faiz) & 1.739 & 0.419 \\
d(log_kur) & $21.857^{*}$ & 0.000 \\
\hline *ve**sirasiyla \%1 ve \%5 istatistikselanlamllik düzeylerini ifade eder. & & \\
\hline & &
\end{tabular}

\section{Sonuç}

Ülkeler küresel ticaretten daha fazla pay elde etmek adına uyguladıkları ekonomi politikaları, sahip oldukları coğrafi konum, üye oldukları iktisadi entegrasyonların mevzuatları ve edindikleri deneyimler doğrultusunda uluslararası ticaret politikalarına yön verirler. Bununla birlikte tüketici ihtiyaçlarındaki farklılaşmalar, küreselleşme hareketleri ve bilgi ve iletişim teknolojisi altyapısındaki hızlı gelişmeler ülkeleri daha çok serbest ticareti ön plana çıkartan ticaret politikalarına yönlendirmiştir.

Uluslararası ticaret alanında faaliyet gösteren firmaların küresel pazarlarda söz sahibi olabilmeleri, sürdürülebilir rekabet gücü elde etmelerine bağlıdır. $\mathrm{Bu}$ bağlamda firmaların mevcut pazarlardaki konumlarını koruyabilmeleri, yeni pazarlara girebilmeleri, ürün çeşitlendirmesinde bulunabilmeleri ve karlılıklarını 
artırabilmelerinde etkin bir teşvik sisteminin varlığı büyük öneme sahiptir. Türkiye'de de 1996 yılından itibaren uygulanmakta olan dahilde işleme rejimi, ekonomik etkili bir gümrük rejimi olarak birçok açıdan katma değer sağlamaktadır.

Ekonomik etkili gümrük rejimlerinin özellikle de dahilde işleme rejiminin birçok avantajı olmasına rağmen rejimin taahhüt edilen ihracat için büyük ölçüde ithalat gerektirmesi, yurt içindeki hammadde ve ara malı madde üreticilerini olumsuz etkilemesi, göreceli olarak vergi gelirlerini azaltması ve istismar edilebilirliğinin söz konusu olması sebepleriyle rejim eleştirilmektedir. Söz konusu bu çalışmada rejimin yurt içi ara malı üretimine olan etkilerini görebilmek adına rejim kapsamında gerçekleştirilen girdi ithalatı ile yurt içi ara malı üretimi ilişkisi 20052019 dönemi için ARDL sınır testi yaklaşımı ile test edilmiştir.

Analiz bulguları dahilde işleme rejiminin Türkiye'de yurtiçi girdi üretimine uzun dönemde herhangi bir etkisi olmadığını gösterirken, kısa dönemde pozitif fakat çok küçük bir etkiye sahip olduğunu göstermiştir. Sonuçlar bu rejimin aslında beklenildiği gibi ihracat sürecinde hızlı girdi temini sağlayarak ihracatı kolaylaştırdığına dair bir fikir vermektedir. Öte yandan kısa dönemdeki pozitif etkinin uzun dönemde sürdürülebilirliğine yönelik politikaların hayata geçirilmesi ülkenin ekonomik dengeleri ile yakından ilişkilidir. Zira cari açığın çok yüksek boyutlarda seyretmesi, kur riski, yerli paranın değer kaybına uğraması veya ithale olan aşırı bağımlılığın öngörülemez seviyelerde seyretmesi halinde yerli girdi üretiminin teşvik edilmesi gündeme gelmelidir. Öte yandan göstergelerin kontrol edilebilir düzeylerde seyretmesi halinde ihracatın teşvikinde dahilde işleme rejiminin yaygınlaştırılması daha doğru olacaktır. 


\section{Kaynakça}

Başkol, M. O. (2016). Türkiye ihracatının ithalata bağımlılığının dahilde işleme rejimi açısından analizi. Ekonomik ve Sosyal Araştırmalar Dergisi, 12(2), $1-18$.

Bustillo, R. ve Rodriguez, C. (2011). The influence of trade union bargaing power on EU processing trade. Journal of Post Keynesian Economics, 33(4), 621644.

Dal, S. (2015). Dahilde işleme rejimi kapsamında Türkiye'de diş ticaret ve döviz kuru ilişkisi (Yayımlanmamış uzmanlık tezi). Türkiye Cumhuriyeti Merkez Bankası, Ankara.

Dickey, D. A. ve W. A Fuller (1979). Distribution of the estimators for autoregressive time series with a unit root. Journal of the American Statistical Association, 74(366), 427-431.

Duru, S., Konuşkan, D. B. ve Parlakay, O. (2017). Inward processing regime promotion system in vegetable oil industry: A case study of Turkey. Turkish Journal of Agriculture-Food Science and Technology, 5(4), 435440.

Eryüzlü, H. (2013). Dahilde işleme rejimi ve cari açık üzerindeki etkileri. İnönü Üniversitesi Uluslararası Sosyal Bilimler Dergisi, 2(1), 59-69.

Gençosmanoğlu, Ö. T. (2016). Dahilde işleme rejiminin Türkiye'de diş ticaret, istihdam ve rekabet gücüne etkileri. Business and Economics Research Journal, 7(2), 83-102.

Mete, E. ve Yıldız, E. B. (2017). Dahilde işleme rejimi ve cari denge: Türkiye için sektörel bir analiz. Uluslararası Bilimsel Araştırmalar Dergisi, 2(7), 3851.

Parlakay, O. ve Duru, S. (2017). Turkiye'de işlenmiş tarım ürünleri dış ticaretinde dahilde işleme rejiminin etkilerinin trend analizi yöntemiyle incelenmesi. Harran Tarım ve Gıda Bilimleri Dergisi, 21(1), 67-72.

Pesaran, M. H., Shin, Y. ve Smith, R.J. (2001). Bounds testing approaches to the analysis of long run relationship. Journal of Applied Econometrics, 16(3), 289-326.

Pomfret, R. ve Sourdin, P. (2009). Have asian trade aggrements reduced trade costs?. Journal of Asian Economics, 20(3), 255-256. 
Sayılgan, G. ve Şenol, C. (2010). Dahilde işleme rejimi ve Türk işletmelerinin ihracat1 üzerine etkileri. Erciyes Üniversitesi İktisadi ve İdari Bilimler Fakültesi Dergisi, 35(Ocak-Temmuz), 37-53.

Şahin, B. E. ve Tekin, Ü. E. (2019). The effects of inward processing regime on foreign trade balance in Turkey (1996-2017). Turkish Studies, 14(3), 14111423.

Şenol, C. (2008). Dahilde işleme rejiminin ihracat üzerine etkileri ile tekstil ve hazır giyim sektörü üzerine bir değerlendirme (Doktora tezi, Ankara Üniversitesi). Erişim adresi: https://www.tk.org.tr/APA/apa_2.pdf

Takım, A. ve Ersungur, Ş. M. (2010). Dahilde işleme rejimi: ihracat ve ithalat üzerindeki etkisi. Atatürk Üniversitesi Iktisadi ve İdari Bilimler Dergisi, 24(2), 289-305.

Tekin, Ü. E. (2017). Dahilde işleme rejiminin ihracat ve ithalat üzerine etkileri (1996-2016). International Journal of Academic Value Studies, 3(16), 192206.

Yıldız, E. B. ve Mete, E. (2018). Türkiye dış ticaretinde ikilem: Dahilde işleme ve ithalata dayalı büyüme. Uluslararası İktisadi ve İdari Incelemeler Dergisi, Prof. Dr. Harun Terzi Özel Sayısı, 319-334. 


\section{The Effect of Import in the context of Inward Processing Regime on Domestic Intermediate Good Production in Turkey: ARDL Boundary Testing Approach}

\section{Extended Abstract}

\section{Introduction}

Countries that adopt free trade have implemented many incentive policies, especially exportoriented, at the point of development and facilitation of international trade. Especially economically-effect customs regime for Turkey is being used as an important incentive tool. The inward processing regime is one of them. This regime is an incentive system that grants exemption from tariffs and similar financial obligations encountered during the import of inputs to be used in the production of goods, if they realize their exports. Also, this regime offers exporters the opportunity to provide the goods they need from other countries in case the goods produced by the producers who provide input to domestic exporters do not have the quality and features required for export or cannot be delivered on time.

When the literature is examined, it is found that there are few studies on inward processing regime. It is seen that some of these studies are based on the analysis of international trade data, and some of them are concluded with the analysis of the effects of the regime on exports. This study aimed to analyze the effect of inward processing regime on domestic intermediate production by focusing on a significant gap in the current literature. Therefore, the main aim of this paper is to investigate the impact of imports under the inward processing regime on domestic intermediate production, by using 2005-2016 monthly data period for Turkey.

\section{Method}

First the stationarity test is carried out by using ADF (Augmented Dickey-Fuller) and PP (PhillipsPerron) unit root tests. Then, in this study, ARDL (Autoregressive Distributed-Lag) boundary approach, which is a current method, is adopted. The most important advantage of the method is that it is suitable for analysis with series, which has different integration degrees. In order to determine the degree of integration, $\mathrm{ADF}$ and $\mathrm{PP}$ unit root tests are performed. Imports under inward processing regime as main explanatory variable and intermediate production index as the dependent variable are obtained from Turkey Statistics Institute. In addition, the indicators of interest rate, exchange rate and producer price index are included in the model as control variables, considering their possible effects on intermediate goods production.

\section{Results and Discussion}

According to the long run coefficient estimation results, the imports under the inward processing regime have a statistically insignificant effect on the domestic intermediate goods production. This result implies that the import of intermediate goods is the more advantageous than production of intermediate goods in Turkey. In other words, it is essential to use imported intermediate goods in export production. While this situation spreads an export-oriented international trade policy, it may lead to excessive import dependency. However, short run coefficient results suggest that imports under inward processing regime have a positive but very slightly effect. Deciding to ensure the sustainability of domestic production increase effect determined for the short run as well in the long run is related to current account deficit, the value of TL and/or the size of the import input dependency. Therefore, although the result obtained from the analysis findings at this point is evaluated in accordance with export-oriented trade, it is also open to different evaluations 
in terms of the current situation of the country in terms of international trade indicators. Also, causality test results show a unidirectional causality relationship running from domestic intermediate good production to imports under inward processing regime.

\section{Conclusion}

The inward processing regime being implemented in Turkey since 1996 provides many economic added values. Although economically-effect customs regimes, especially the inward processing regime, have many advantages, the regime is criticized for the fact that the regime requires a large amount of imports for the committed export, negatively affects domestic producers of raw materials and intermediate goods. The results of this study give an idea that this regime facilities export by providing rapid input in the export process as expected. On the other hand, the implementation of policies in order to sustain the positive effect observed in the short run is closely related to the economic balances of the country. Indeed, encouragement of domestic input production should come to the fore when the current account deficit is at very high levels, exchange rate risk, depreciation of the domestic currency or excessive dependency on imports is at unpredictable levels. However, if the indicators are at controllable levels, it would be more appropriate to expand the inward processing regime for export promotion. 